\title{
The cubic regression model of thermal estimation in the flammability test of the fibrous compound used in bus bodies
}

\author{
Cristian Pérez-Salinas ${ }^{1, a}$, Christian Castro $^{1}$ and Roberto Valencia ${ }^{1}$ \\ ${ }^{1}$ Universidad Técnica de Ambato, Facultad de Ingeniería Civil y Mecánica, Research group in materials and production, Av. Los Chasquis \\ and Río Payamino, Ecuador
}

\begin{abstract}
The fire behavior of fiber compounds is a serious concern in automotive applications. The objective of the proposed work is to predict thermal behavior during flammability testing of the composite material of polymer matrix reinforced with fiberglass used in the interior lining of bodies. Different regression models were performed to determine the best fit. This regression analysis determines the existing correlation between the acquired parameters of burn time and temperature versus two types of fibers used for the interior decorative lining. Different regression coefficients were determined and used for the prediction. Through the best fit regression model, thermal behavior of burning during the flammability test is predicted under ISO standard 3795: 1989 and FMVSS 302. The prediction was made for two types of composites, Roof Fiber, FT, and Fiber for laterals, FL. The cubic regression model showed the best prediction fit with a Rq of 0.79 for FT and 0.81 for FL.
\end{abstract}

\section{Introduction}

Accidents caused by burning of vehicles has been a constant concern worldwide for the material and human losses that this has entailed. However, the situation differs in different countries. In the US the percentage has decreased substantially but the number is still important $[1,2]$. In European countries an increase in numbers has been a constant over time with some decrease in the percentage in recent years [3-5]. Although in Latin America there are no official figures, the report of the written press about the increase in vehicle fires, especially in buses, has increased alarmingly [6-8]. Por lo tanto, la prevención de incendios de vehículos de transporte público es uno los problemas más graves de las estancias gubernamentales $[9,10]$.

Today, textiles, polymers, composites and various biomaterials are the raw material for the assembly of bodies. A great degree of these materials have an active behavior before the fire. Several investigations have focused on the mechanical characterization and study of technological properties such as their flammability indexes with the intention of improving their behavior in the face of a flame [11-13].

There is a large database available about ignition time, rate of heat released, oxygen index, flame propagation, smoke release and toxicity. At the same time, there have been advances in the development of models for calculating certain properties and estimates of reaction to fire, such as the rate of heat release and the ignition time.

Modeling fire behavior of materials has a great complexity since this phenomenon involves the action of several processes such as chemical, physical, thermal and failure $[14,15]$. Given this complexity, the disintegration and study of the different processes allow us to estimate interpreting and predicting the fire behavior of the different materials.

Within the automotive industry, textile, polymer and resinous composites are widely used as structural and decorative materials. Buses use polymer matrix composite materials reinforced with glass fiber to cover the structure of the body interiorly, structurally and decoratively, for example, we have the covering of ceilings, side and rear walls, control panels, drawers, etc. Fire performance is one of the most important factors considered in the design process of products and systems. Therefore, this document describes predictive models of the thermal behavior during the flammability test under ISO 3795: 1989 and FMVSS 302 of glass fiber reinforced polymer matrix composite materials for bus interior application. Allowing to obtain important information for the control and use of materials that benefit the safety of the passengers.

\section{Metodology}

\subsection{Experimental Development}

For the study, composite polymer matrix materials reinforced with fiberglass (fiber for roof, fiber for side walls) stratified originally from car body factories where several samples were taken. Some important mechanical

\footnotetext{
a Corresponding author: cf.perez@uta.edu.ec
} 
and technological properties were previously obtained as shown in table 1 .

Table 1. Main mechanical and technological properties of fiberglass reinforced polymer matrix composite materials.

\begin{tabular}{|l|c|c|c|}
\hline \multicolumn{1}{|c|}{ Property } & Standard & Unit & Value \\
\hline Tensile strength & ASTM D638 & $\mathrm{MPa}$ & 108 \\
\hline Stretch elongation & ASTM D638 & $\% @ 25^{\circ} \mathrm{C}$ & 1,9 \\
\hline Flexural strength & ASTM D790 & $\mathrm{MPa}$ & 244 \\
\hline Flammability index & ISO 3795 & $\mathrm{~mm} / \mathrm{min}$ & 30,58 \\
\hline
\end{tabular}

Specimens were of dimensions $100 \mathrm{~mm}$ wide, $356 \mathrm{~mm}$ long and up to $13 \mathrm{~m}$ thick, as prescribed in ISO 3795 : 1989 [16], on an Atlas combustion chamber model HMW under norm FMVSS 302 [17]. A control system (Arduino MEGA 2560 R3 card) was installed to sense the flame temperature inside the chamber through an infrared thermal sensor. The signals were interpreted through the LABVIEW software as shown in the scheme of figure 1.

The specimens were made in shape and dimensions $100 \mathrm{~mm}$ wide, $356 \mathrm{~mm}$ long and up to $13 \mathrm{~mm}$ thick; prescribed in the ISO standard mentioned.

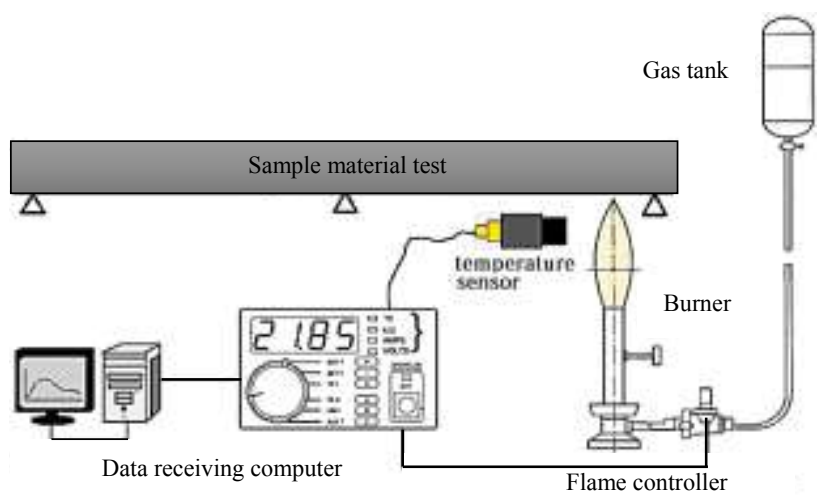

Figure 1. Experimental scheme.

\subsection{Statistic Analyses}

Six regression models were evaluated to select the best thermal behavior adjustment during the flammability test time. The models evaluated were: Linear, quadratic, cubic, compound, growth and exponential [18].

The selection of the model of best fit provision for each variable was made based on four statistical criteria. An analysis of variance of the regression, coefficients of determination (R2) and significance of the model were made to analyze the goodness of fit of said models. The statistical software "SPSS Estudio" was used to process the data to obtain a thermal behavior model.

\section{Results and Discussion}

Table 2 shows the results of the measurements obtained by the temperature sensor close to the initial point of the flammability test measured during the average test time in composites (1500 sec).

Due to the prolonged time of resulting flammability test, side fiber (FL) and roof fiber (FT) are considered non-self-extinguishing materials. The standard flame length at the start of the test was $38 \mathrm{~mm}$. When extinguishing flames after the normed time, it was shown that the speed of transmission of the flame or burn of the material propagated constantly until consuming the total length of the test pieces (figure 2).

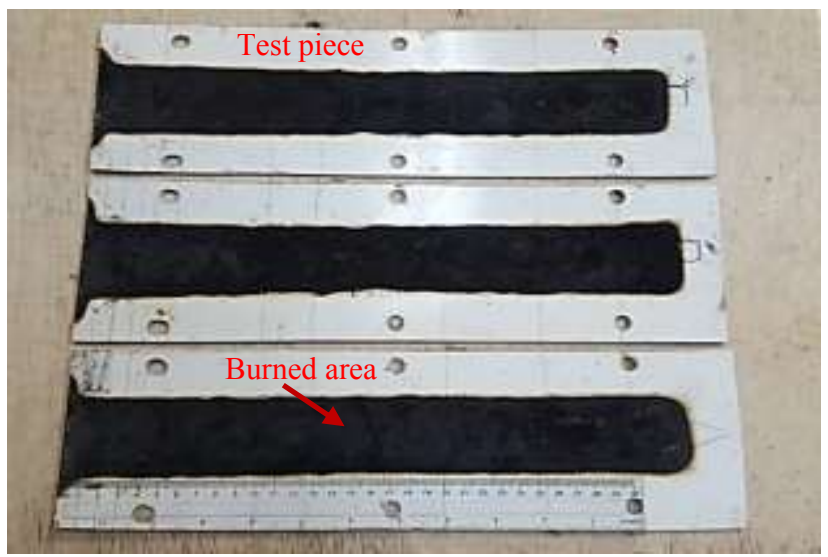

Figure 2. Burned test tubes of flammability test.

Table 2. Temperatures inside the chamber during the time of the flammability test for the FT and FV composites.

\begin{tabular}{|c|c|c|c|c|c|}
\hline $\begin{array}{c}\text { Time } \\
(\mathbf{s e g})\end{array}$ & $\begin{array}{c}{ }^{\circ} \mathbf{T} \text { sensor } \\
\text { FT }\left({ }^{\circ} \mathbf{C}\right)\end{array}$ & $\begin{array}{c}{ }^{\circ} \mathbf{T} \text { sensor } \\
\text { FL }\left({ }^{\circ} \mathbf{C}\right)\end{array}$ & $\begin{array}{c}\text { time } \\
(\mathbf{s e g})\end{array}$ & $\begin{array}{c}{ }^{\circ} \mathbf{T} \text { sensor } \\
\text { FT }\left({ }^{\circ} \mathbf{C}\right)\end{array}$ & $\begin{array}{c}{ }^{\circ} \mathbf{T} \text { sensor } \\
\text { FL }\left({ }^{\circ} \mathbf{C}\right)\end{array}$ \\
\hline 0 & 45,00 & 35,75 & 360 & 224,17 & 224,13 \\
\hline 1 & 44,04 & 35,66 & 390 & 226,66 & 234,96 \\
\hline 3 & 41,47 & 33,71 & 420 & 223,18 & 240,25 \\
\hline 6 & 40,27 & 33,06 & 450 & 219,02 & 238,62 \\
\hline 9 & 40,46 & 32,92 & 480 & 208,09 & 235,54 \\
\hline 12 & 40,92 & 33,34 & 510 & 196,28 & 224,9 \\
\hline 15 & 41,50 & 33,45 & 540 & 186,79 & 210,99 \\
\hline 18 & 42,40 & 33,72 & 570 & 177,96 & 192,11 \\
\hline 21 & 43,46 & 34,12 & 600 & 170,73 & 179,73 \\
\hline 24 & 44,28 & 34,7 & 660 & 152,84 & 150,84 \\
\hline 27 & 45,32 & 35,09 & 720 & 128,71 & 125,56 \\
\hline 30 & 46,32 & 35,78 & 780 & 113,81 & 105,72 \\
\hline 60 & 55,58 & 44,4 & 840 & 100,53 & 91,05 \\
\hline 90 & 71,96 & 56,2 & 900 & 88,12 & 82,33 \\
\hline 120 & 87,04 & 70,85 & 960 & 82,43 & 77,06 \\
\hline 150 & 102,68 & 87,7 & 1020 & 77,91 & 73,83 \\
\hline 180 & 121,05 & 106,7 & 1080 & 74,94 & 70,47 \\
\hline 210 & 146,04 & 129,1 & 1230 & 67,96 & 66,85 \\
\hline 270 & 188,62 & 170,69 & 1380 & 63,46 & 62,37 \\
\hline 300 & 205,88 & 191,75 & 1530 & 61,15 & 59,1 \\
\hline 330 & 219,32 & 208,66 & - & - & - \\
\hline
\end{tabular}

Once the statistical data treatment was carried out, it was determined that the "cubic model" provided a better adjustment of the thermal behavior during the flammability tests. Figures 3,4,5,6 graphically appreciate the fit of each model with respect to the experimental measurements observed.

Table 3. Summary of the best model adjustment.

\begin{tabular}{|c|c|c|c|c|}
\hline Material & $\mathbf{R}$ & $\begin{array}{c}\mathbf{R} \\
\text { square }\end{array}$ & $\begin{array}{c}\text { R square } \\
\text { adjusted }\end{array}$ & $\begin{array}{c}\text { Standard } \\
\text { error estimate }\end{array}$ \\
\hline FT1 & 0,886 & 0,785 & 0,769 & 31,856 \\
\hline FT2 & 0,807 & 0,651 & 0,636 & 38,499 \\
\hline FL1 & 0,900 & 0,810 & 0,796 & 33,256 \\
\hline
\end{tabular}




\begin{tabular}{l|c|c|c|c|}
\hline FL2 & 0,849 & 0,720 & 0,708 & 33,058 \\
\hline Fiber roof replica 1 (FT1) & Fiber roof replica 1 (FT1) \\
Fiber walls replica 1 (FL1) & Fiber walls replica 2 (FL2) \\
$*$ The independent variable is time.
\end{tabular}

Table 4. ANOVA data analysis for each material.

\begin{tabular}{|l|c|c|c|c|c|}
\hline \multicolumn{1}{|c|}{ item } & $\begin{array}{c}\text { Sum of } \\
\text { squares }\end{array}$ & gl & $\begin{array}{c}\text { quadratic } \\
\text { mean }\end{array}$ & F & Sig. \\
\hline Fiber roof replicate 1 (FT1) \\
\hline Regression & 151912,09 & 3 & 50637,365 & 49,90 &, 000 \\
\hline Residue & 41605,84 & 41 & 1014,777 & & \\
\hline Total & 193517,93 & 44 & & & \\
\hline Fiber roof replicate 2 (FT2) & \\
\hline Regression & 196360,91 & 3 & 65453,636 & 44,160 &, 000 \\
\hline Residue & 105235,02 & 71 & 1482,183 & & \\
\hline Total & 301595,93 & 74 & & & \\
\hline Fiber walls replicate 1 (FL1) & & \\
\hline Regression & 189040,29 & 3 & 63013,432 & 56,976 &, 000 \\
\hline Residue & 44238,721 & 40 & 1105,968 & & \\
\hline Total & 233279,01 & 43 & & & \\
\hline Fiber walls replicate 2 (FL2) & & \\
\hline Regression & 199733,12 & 3 & 66577,706 & 60,922 &, 000 \\
\hline Residue & 77591,721 & 71 & 1092,841 & & \\
\hline Total & 277324,84 & 74 & & & \\
\hline
\end{tabular}

Table 5. Coefficients of cubic model determined.

\begin{tabular}{|c|c|c|c|c|c|}
\hline \multirow{2}{*}{ item } & \multicolumn{2}{|c|}{$\begin{array}{c}\text { Non-standardized } \\
\text { coefficients }\end{array}$} & \multirow{2}{*}{$\begin{array}{c}\begin{array}{c}\text { Standardized } \\
\text { coefficients }\end{array} \\
\text { Beta }\end{array}$} & \multirow[b]{2}{*}{ t } & \multirow{2}{*}{ Sig. } \\
\hline & B & $\begin{array}{c}\text { Standar } \\
\text { d error }\end{array}$ & & & \\
\hline \multicolumn{6}{|c|}{ Fiber roof replicate 1 (FT1) } \\
\hline$\left({ }^{\circ} \mathrm{T}\right)$ & 0,615 & 0,054 & 5,453 & 11,458 & $\overline{0,00}$ \\
\hline$\left({ }^{\circ} \mathrm{T}\right) * * 2$ & $-0,001$ & 0 & $-12,783$ & $-10,36$ & 0,00 \\
\hline$\left({ }^{\circ} \mathrm{T}\right) * * 3$ & $2,37 \mathrm{E}-07$ & 0 & 7,494 & 9,027 & 0,00 \\
\hline \begin{tabular}{|l|} 
(Constant) \\
\end{tabular} & 40,727 & 8,752 & & 4,654 & 0,00 \\
\hline \multicolumn{6}{|c|}{ Fiber roof replicate 2 (FT2) } \\
\hline$\left({ }^{\circ} \mathrm{T}\right)$ & 0,425 & 0,066 & 4,201 & 6,433 & 0,00 \\
\hline$\left({ }^{\circ} \mathrm{T}\right) * * 2$ & $-0,001$ & 0 & $-11,974$ & $-7,606$ & 0,00 \\
\hline$\left({ }^{\circ} \mathrm{T}\right) * * 3$ & $1,71 \mathrm{E}-07$ & 0 & 7,413 & 7,476 & 0,00 \\
\hline (Constant) & 83,593 & 15,748 & & 5,308 & 0,00 \\
\hline \multicolumn{6}{|c|}{ Fiber walls replicate 1 (FL1) } \\
\hline$\left({ }^{\circ} \mathrm{T}\right)$ & 0,742 & 0,06 & 5,494 & 12,327 & 0,00 \\
\hline$\left({ }^{\circ} \mathrm{T}\right) * * 2$ & $-0,001$ & 0 & $-12,404$ & $-10,88$ & 0,00 \\
\hline$\left({ }^{\circ} \mathrm{T}\right) * * 3$ & $3,12 \mathrm{E}-07$ & 0 & 7,159 & 9,38 & 0,00 \\
\hline \begin{tabular}{|l|} 
(Constant) \\
\end{tabular} & 24,605 & 9,22 & & 2,669 & 0,011 \\
\hline \multicolumn{6}{|c|}{\begin{tabular}{|l} 
Fiber walls replicate 2 (FL2) \\
\end{tabular}} \\
\hline$\left({ }^{\circ} \mathrm{T}\right)$ & 0,482 & 0,057 & 4,967 & 8,495 & 0,00 \\
\hline$\left({ }^{\circ} \mathrm{T}\right) * * 2$ & $-0,001$ & 0 & $-13,446$ & $-9,538$ & 0,00 \\
\hline$\left({ }^{\circ} \mathrm{T}\right) * * 3$ & $1,81 \mathrm{E}-07$ & 0 & 8,142 & 9,171 & 0,00 \\
\hline (Constant) & 66,278 & 13,523 & & 4,901 & 0,00 \\
\hline
\end{tabular}

Table 3 shows the result of the cubic model of best fit for each material tested. A cubic prediction can be made, since it has an adjustment of the model, greater than 0.7 of $\mathrm{R}$ squared and a relation between the two variables positive average of 0.85 for the two materials tested with their respective replicas (Table 3).

The ANOVA analyzes for all replicas show that the modeling of the cubic regression is appropriate, since the level of significance is zero for all cases (Table 4).

Table 5 shows the coefficients of the cubic model, the constant, the coefficient of the variable, the coefficient of the quadratic variable and the coefficient of the cubic variable. Each of them is significant, that is, they have a value less than 0.05 with a confidence level of $95 \%$. In this way, the four equations or cubic models are formed to make a prediction of the time and temperature variable.

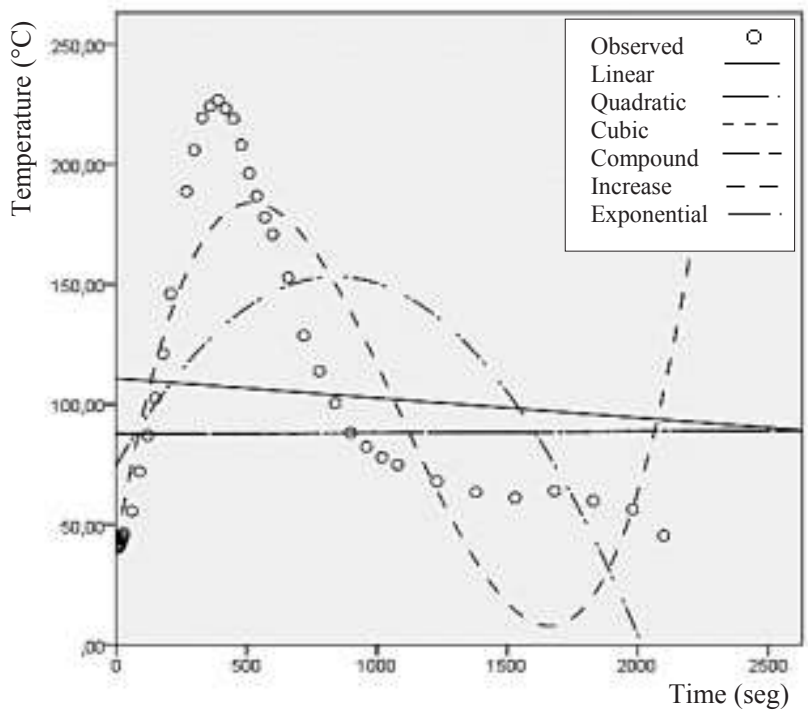

Figure 3. Regression models for thermal behavior of FT1

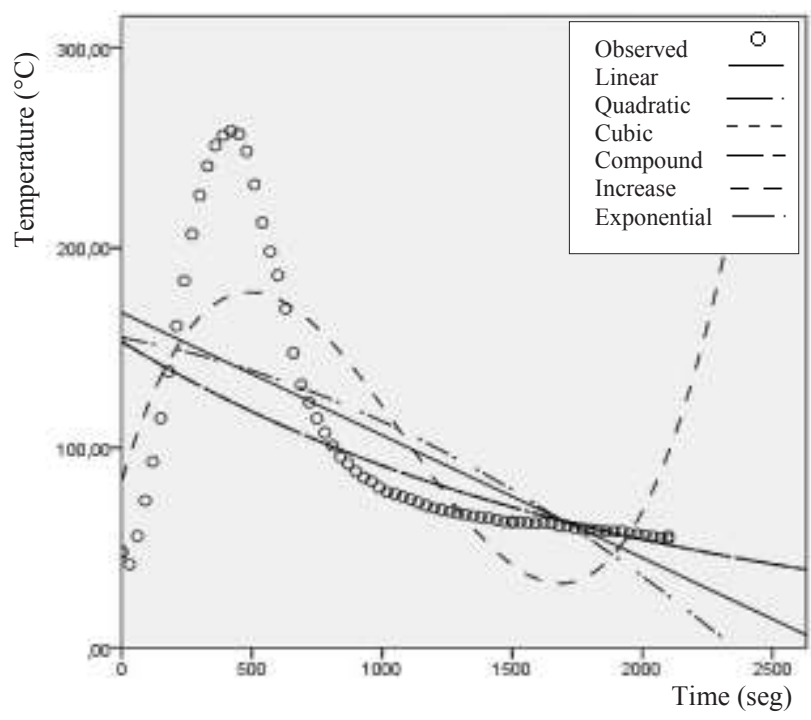

Figure 4. Regression models for thermal behavior of FT2

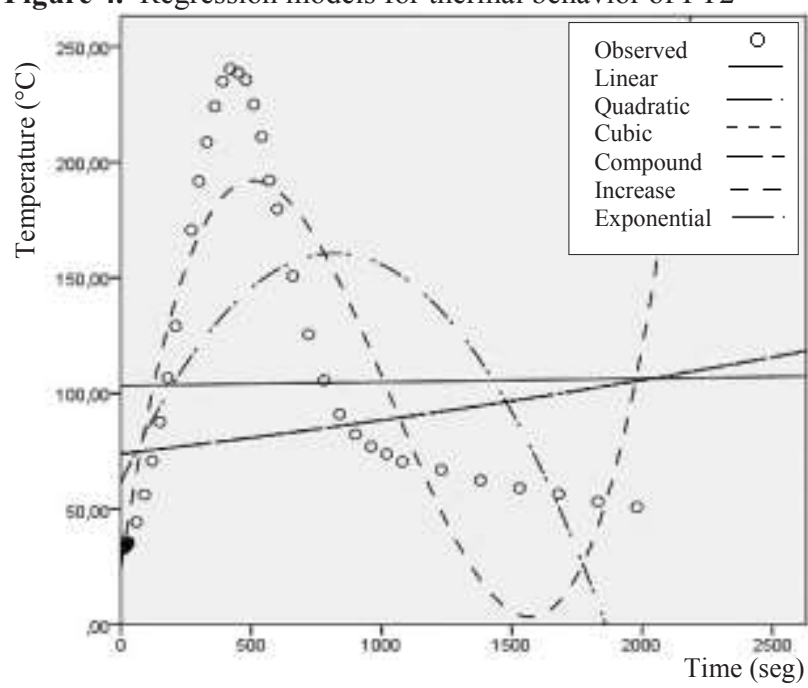

Figure 5. Regression models for thermal behavior of FL1 


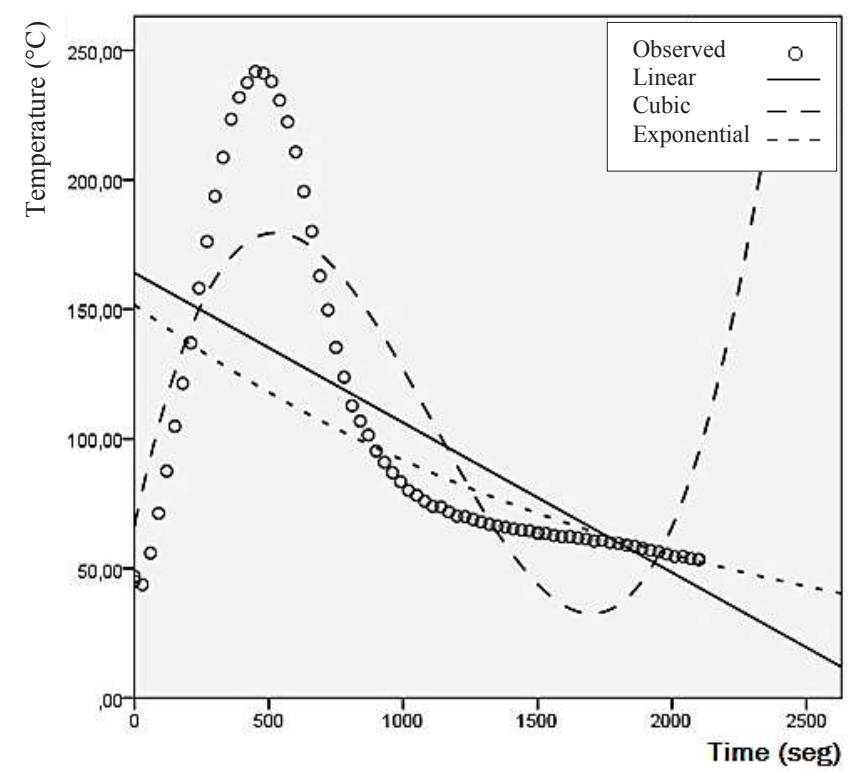

Figure 6. Regression models for thermal behavior of FT1

The obtained equations representing the in-chamber temperature modeling for roof composites (FT) and for side walls (FL) during the initial experimentation and their replications observe in equations $1,2,3$ and 4 respectively:

$$
\begin{aligned}
& \text { MeanFT }_{1}=40,73+0,62\left({ }^{\circ} \mathrm{T}\right)-0,001\left({ }^{\circ} \mathrm{T}\right)^{2}+2,37 \times 10^{-7}\left({ }^{\circ} \mathrm{T}\right)^{3} \\
& \text { MeanFT }_{2}=83,60+0,43\left({ }^{\circ} \mathrm{T}\right)-0,001\left({ }^{\circ} \mathrm{T}\right)^{2}+1,71 \times 10^{-7}\left({ }^{\circ} \mathrm{T}\right)^{3} \\
& \text { MeanFL }_{1}=24,61+0,74\left({ }^{\circ} \mathrm{T}\right)-0,001\left({ }^{\circ} \mathrm{T}\right)^{2}+3,12 \times 10^{-7}\left({ }^{\circ} \mathrm{T}\right)^{3} \\
& \text { MeanFL }_{2}=66,28+0,48\left({ }^{\circ} \mathrm{T}\right)-0,001\left({ }^{\circ} \mathrm{T}\right)^{2}+1,81 \times 10^{-7}\left({ }^{\circ} \mathrm{T}\right)^{3}
\end{aligned}
$$

Analyzing each of the prescribed equations, it follows that the regression models that best adapt for a statistically reliable prediction are equations 1 and 4 . This is because it has a higher Fisher coefficient of determination $(F=49.90$ and $F=60.92)$ for each respective material, which means that the models come from. All the coefficients are statistically significant since they are less than 0.05 , with a confidence level of $95 \%$. Consequently, we can predict the thermal behavior of the composite material of polymer matrix reinforced with glass fiber for roof and side walls individually. Starting from the fact that the two applications are made with the same material, but with different number of layers and different thickness of surface treatment (Gelcoat to texturize it), it can be said that the best predictive model is equation 4 because of its higher coefficient value from Fisher $(\mathrm{F}=60.92)$. This is supported by the fact that the results of the thermal behavior inside the chamber have significant differences.

\section{Conclusion}

Unlike other structural materials such as steel, aluminum alloy and reinforced concrete, the compounds are reactive materials at high temperature due to the polymer matrix that has. Consequently many authors have reported the need to incorporate additives [15, 19].
Regression models have been applied in different fields and are a valuable tool in the study and interpretation of systems with diverse characteristics $[10$, 20-22].

All the models analyzed, the cubic regression model shows the best fit to the phenomenon studied. Equations 1 and 4 present the best prediction of the thermal behavior for the FT and FL composites respectively, all coefficients being significantly lower than 0.05 , with a confidence level of $95 \%$.

The thermal models developed to calculate the temperature distribution inside the combustion chamber under norm ISO 3795: 1989 and FMV 302 in the laminated compounds studied can predict with good precision the behavior of the temperature, according to the statistical results found in the Table 3. This is consistent with what has been mentioned in similar studies that indicate the importance of analyzing parallel phenomena such as physicists and chemists to better understand the behavior of these materials in the face of fire. [23-25]. On the other hand, also the importance of analyzing other materials such as textiles, thermoplastics that are also used in the manufacture of buses and automobiles.

The burning temperature of the materials reaches its peak $\left(238^{\circ} \mathrm{C}\right.$ for $\mathrm{FL}$ and $224^{\circ} \mathrm{C}$ for $\left.\mathrm{FT}\right)$ at an average time of 400 seconds from the start of combustion and remains at a temperature higher than $200^{\circ} \mathrm{C}$ during a time of 150 to 200 seconds. The thermal energy deployed in the lateral fiber (FL) is slightly higher than in the roof fiber (FT) because the "Gelcoat" (coating material for surface texture copy) has greater thickness to be mixed with decorative coloring additive in FL, as it is also due to the fact that said fiber has an additional layer of fiberglass with respect to FT.

\section{References}

[1] M. Ahrens, "Trends and patterns of US fire loss," National Fire Protection Association (NFPA) report Google Scholar, 2017.

[2] M. Ahrens, US vehicle fire trends and patterns: National Fire Protection Association, 2010.

[3] B. Reinicke, J. Axelsson, and R. Hammarström, "Bus and coach fires in Sweden and Norway," ed, 2006.

[4] Y. Li and M. Spearpoint, "Analysis of Vehicle Fire Statistics in New Zealand Parking Buildings," Fire Technology, vol. 43, pp. 93-106, June 012007.

[5] A. Hofmann and S. Dülsen, "Fire safety performance of buses," Fires in Vehicles-FIVE 2012, p. 147, 2012.

[6] Periódico, "El pais" publicación 04 de julio de 2018," ed: Colombia.

[7] Periódico, "El Telégrafo", publicación de 04 de septiembre de 2018," ed: Ecuador.

[8] Periódico, "El Heraldo" publicación de 25 de febrero de 2018.," ed: Ecuador.

[9] A. Cordner, M. Mulcahy, and P. Brown, "Chemical regulation on fire: rapid policy advances on flame retardants," Environmental science \& technology, vol. 47, pp. 7067-7076, 2013.

[10] L. H.-s. Z. Xin-lei and S. Li-xia, "Comprehensive Evaluation and Prediction of Fire Accidents in China 
Based on Statistics [J]," China Safety Science Journal, vol. 6, p. 010, 2011.

[11] C. Q. Yang, Q. He, R. E. Lyon, and Y. Hu, "Investigation of the flammability of different textile fabrics using micro-scale combustion calorimetry," Polymer Degradation and Stability, vol. 95, pp. 108$115,2010 / 02 / 01 / 2010$.

[12] D. Gao, R. Li, B. Lv, J. Ma, F. Tian, and J. Zhang, "Flammability, thermal and physical-mechanical properties of cationic polymer/montmorillonite composite on cotton fabric," Composites Part B: Engineering, vol. 77, pp. 329-337, 2015/08/01/2015.

[13] H. Yang, Q. Fu, X. Cheng, R. K. K. Yuen, and H. Zhang, "Investigation of the Flammability of Different Cables Using Pyrolysis Combustion Flow Calorimeter," Procedia Engineering, vol. 62, pp. 778785, 2013/01/01/ 2013.

[14] A. Mouritz, S. Feih, E. Kandare, Z. Mathys, A. Gibson, P. Des Jardin, et al., "Review of fire structural modelling of polymer composites," Composites Part A: Applied Science and Manufacturing, vol. 40, pp. 1800-1814, 2009.

[15] M. Prabhakar, A. U. R. Shah, and J.-I. Song, "A review on the flammability and flame retardant properties of natural fibers and polymer matrix based composites," Polymer, vol. 37, p. 40, 2015.

[16] ISO, "ISO 3795: 1989. Road vehicles, and tractors and machinery for agriculture and forestry -Determination of burning behaviour of interior materials," p. 6.

[17] FMVSS, "FMV 302 Flammability of interior materials," Federal Motor Vehicles Safety Standards.

[18] R. B. Darlington and A. F. Hayes, Regression analysis and linear models: Concepts, applications, and implementation: Guilford Publications, 2016.

[19] A. Subasinghe, R. Das, and D. Bhattacharyya, "Study of thermal, flammability and mechanical properties of intumescent flame retardant $\mathrm{PP} /$ kenaf nanocomposites," International Journal of Smart and Nano Materials, vol. 7, pp. 202-220, 2016.

[20] L. Rodríguez, V. Torres, R. O. Martínez, O. Jay, A. C. Noda, and M. Herrera, "Modelos para estimar la dinámica de crecimiento de Pennisetum purpureum vc. Cuba CT-169," Revista cubana de ciencia agrícola, vol. 45, 2011.

[21] S. Chithra, S. S. Kumar, K. Chinnaraju, and F. A. Ashmita, "A comparative study on the compressive strength prediction models for High Performance Concrete containing nano silica and copper slag using regression analysis and Artificial Neural Networks," Construction and Building Materials, vol. 114, pp. 528-535, 2016.

[22] P. V. Parandekar, A. R. Browning, and O. Prakash, "Modeling the flammability characteristics of polymers using quantitative structure-property relationships (QSPR)," Polymer Engineering \& Science, vol. 55, pp. 1553-1559, 2015.

[23] F. Gharagheizi, "Prediction of upper flammability limit percent of pure compounds from their molecular structures," Journal of Hazardous Materials, vol. 167, pp. 507-510, 2009/08/15/2009.

[24] A. Bilal, R. J. T. Lin, and K. Jayaraman, "Optimisation of material compositions for flammability characteristics in rice husk/polyethylene composites," Journal of Reinforced Plastics and Composites, vol. 33, pp. 2021-2033, 2014/11/01 2014.

[25] H. Yaghoobi and A. Fereidoon, "Thermal analysis, statistical predicting, and optimization of the flexural properties of natural fiber biocomposites using Box-
Behnken experimental design," Journal of Natural Fibers, pp. 1-19, 2018. 